\title{
Girls Drop Out of School: Challenges and Countermeasures for Girls' Education in the Western Ecological Migration Area
}

\author{
X.M. GUAN \\ Jiuquan Vocational and Technical College, Jiuquan, Gansu, China \\ L.M. WANG \\ Teaching and Research Office of Jiuquan City Education Bureau, Gansu, China
}

\begin{abstract}
This paper takes Guazhou County, Gansu Province as the research blueprint for the western ecological migration area, girls who drop out of school in the region as the research object, conducts research on the situation of girls who drop out of school through interviews, explores the related causes, and tries to give some advice, wishing to provide some suggestions for the development of girls' education in western ecological migration area, making them receive a complete nine-year compulsory education, improving their cultural quality, and achieving a sustainable development.
\end{abstract}

KEYWORD: Ecological migration area; Girls drop out of school; Causes; Countermeasures

\section{INTRODUCTION}

It is an indisputable fact that western education lags behind the average level of the country, in which the basic education is particularly evident, especially in rural areas, ethnic minority areas. Among which girls' education is a top priority which cannot be ignored, and the problem that girls drop out of school in the most difficult. Since the 1980s, relying on "Shule River Project," "Jiudianxia Project" and other water conservancy constructions, Gansu Province implements a large-scale "Two West Ecological Migration Project", making the people of the eastern arid region and southern cold and humid region of Gansu province migrate to the counties of Hexi Corridor. As an important migration destination, up to 2013, Guazhou County has undertaken a total of nearly 80,000 migrants. This research takes the migrant school girls of the whole organizational system in Guazhou County as the research object, trying to tease out the crux, analyze the reasons of why girls drop out of school and put forward some targeted strategies and ways to improve it. Based on the literature research and data compilation, this paper conducts interview investigation, which mainly centers on the reasons for the dropping out of school of girls. Survey shows: since 2004, although Guazhou County has been implementing the national policy "two exemptions and one subsidy", increasing the education investment for the immigrant area, promoting the reform and development of education comprehensively, the situation of low enrollment of girls has been improved, basically reaching the two- base acceptance criteria, but the increase of the enrollment rate does not fully reflect the plight of girls' education, the big ratio fluctuations reveal many deeper dilemma of girls' education in the region: the "high" enrollment rate of girls and the "low" graduation rate and retention rate form a tremendous contrast. The task of protecting the education right of minority girls effectively is still arduous.

\section{RESEARCH RESULTS AND ANALYSIS}

\subsection{The Overall Situation}

The girl dropout rate of grade four to six in elementary school, grade two and three in junior high school of Guazhou County is the peak. Among the sixty girl interviewees, there are thirty-nine dropouts of grade four to six, accounting for $65 \%$ of the total number of interviewees; there are seventeen dropouts of grade two and three in junior high school, accounting for $28.3 \%$ of the total number of interviewees; active dropouts is in the majority, accounting for $58 \%$ of the total number of interviewees; the girl-dropout pattern shows the obvious characteristics that the girl dropout rate of ethnic minorities is higher than the Han nationality.

\subsection{Causes Analysis of Dropout}

\subsubsection{Girls Self Respect}

(1) Poor academic performance. The weariness caused by poor academic performance is an important reason for the school girl dropouts. 
Among the sixty girl interviewees, there are fortytwo girls who say that they cannot keep up with their learning during the school, and always get bad grades, especially afraid of the exams, because after the exam results are announced, they are always criticized by teachers, laughed at by classmates, therefore producing an inferiority complex. Especially after entering higher grades, especially after entering junior middle school, there are more school subjects and more difficult learning, the original labored learning becomes more difficult, so they gradually lose confidence in learning, and eventually leave the school.

(2) Lack of learning interest and motivation. The school girls of Guazhou County come from different regions of Gansu province, there are big differences between the former residence and resettlement areas in aspects such as living environment, customs and habits, school education. After entering the new environment, the girls will produce many maladjustments, especially limited by the dialect, they have learning difficulties at school, plus that their academic performance is not ideal, so they gradually lose interest in learning and motivation, and many of them choose to leave the school. Thirtysix girls among the interviewees say that they themselves does not adapt to the new living and learning environment, and have fear in their hearts.

(3) Physiological and psychological changes of puberty. When girls reach the age of eleven, that is five or six grades of primary school, their bodies begin to develop gradually, and their psychological changes are also obvious accordingly. They become sensitive, shy, and have a strong self-esteem, and begin to close themselves in front of adults. When encountered difficulties in school, they are not willing to communicate with their parents, but to make decisions themselves or discuss with classmates. Sometimes criticized by the teacher in school, or see the kids in the neighborhood who drop out of school at home are also very good, so they don't communicate with their parents, and drop out of school themselves.

\subsubsection{Family Respect}

(1) Economic difficulties. After the migrants migrate into Guazhou County, although the production and life conditions have some improvements compared with the original residence, the land production capacity is low, coupled with the irrigation and water conservancy facilities don't match, and immigrants lack the necessary production skills, the life of most immigrants remains difficult. In such cases, the eldest son of home, especially the girls are particularly vulnerable to drop out of school. Twenty-three girls of the interviewees are the eldest daughters, dropping out of school is in order to earn money to supplement the family or take care of younger siblings.
(2) Low educational level of parents. Most emigration counties of Guazhou County are in the mountainous area. According to the 2011 data of the local Poverty Relief Office, in the cultural structure of the immigrant population of Guazhou County, the rate of illiteracy and primary school education is as high as $85.2 \%$.Among the parents of the sixty interviewees, illiterate and semi-literate accounts for more than $68 \%$, and only six people receive junior high school or higher education. This makes them cannot aware of the importance of education for their children to grow, therefore cannot guarantee to provide a good education environment for their children. In their view, as long as the children know some Chinese characters, can write his own name, and know simple arithmetic, that is sufficient.

(3) Too many children in a single family. In Guazhou County, the ethnic minorities occupies a large proportion, and the phenomenon that there are three or four children in a single family is common. When the family resources are limited, compared with the girls, the boys often have priority in terms of resources possession.[1] This is why the dropouts tend to be girls. And many children do not attend school or their school time is very short in the original residence, so after moving to the new school, their age is generally older than others. Among the interviewees, nine children who are at the age of ten are just in grade one in elementary school, thirteen children who are at the age of fifteen or sixteen are still in the primary school. They become the "highrisk" dropouts naturally, and are difficult to finish the nine-year compulsory education.

\subsubsection{School Respect}

(1) Curriculum setting. Guazhou County arranges courses in accordance with the unified arrangement of national curriculum standards and local educational administrative departments, thus fails to meet the real purposes and requirements of the girls themselves and their families. The curriculum is a bit more difficult on the whole for the immigrant students, which is also an important reason for the high school dropout rate of this region, especially for the girls. Among the interviewees, forty-five children feel the schoolwork is difficult, and they do not understand in class, and feel boring.

(2) Teachers' attitude. There is a high proportion of young and middle-aged teachers, accounting for more than $72 \%$ of the total number of teachers in Guazhou County, and quite a number of them are non-normal specialized graduates. Because of the lack of systematic learning experience of educational theories, and lack of experience in education teaching and student management, the phenomenon of giving up on, ridicule, and punish student corporally is relatively common. Combined with some teachers are affected by the idea of "the male learns sciences and the female learns arts", thinking 
that girls are weaker than boys in science learning on the whole. The teachers' attitude leads the girls to internalize this attribution pattern, thus their selfconfidence declines. [2]Among the interviewees, forty-four students say that mathematics is the most difficult course to learn, and their academic performance of mathematics is the worst.

(3) School management. Most immigrant schools in Guazhou County are newly built. In the early times, in order to improve the school environment, the schools occupy the class time to varying degrees to mobilize the teachers and students of different level to level off campus, harden the roads and so on. Therefore, many parents feel that it is better to do their own work at home than sending their children to school to work. Coupled with the lack of school education and teaching facilities, and inadequate school buildings, school education and family education cannot be effectively connected, plus that off-campus deregulation, all the reasons above cause students a weak sense of security and belonging. Among the interviewees, there are twenty-six people who dropped out of school because of this reason.

\subsubsection{Social Factors}

(1) The influence of traditional concepts. The ideology of male superiority is entrenched among the immigrant masses in Guazhou County, which attaches great emphasis on the role that the male plays in social production and family life, and thinks that "daughters are spilled water, and they are other family's person after all"," it is enough for the girls to write their own name, and recognize some Chinese characters". This kind of psychological concept has subtle impact on girls, "cultivating" their psychology of inferiority and attachment, etc., so that they are lack of confidence, lack the courage to participate in the competition, once encountered difficulties and failures, they are easy to become discouraged, even give up.[3]

(2) The impact of the economic tide. Guazhou County is a major agricultural county, its pillar industries are crops such as cotton, and Chinese wolfberry, whose cultivation management is highly seasonal, and require a lot of labor when the harvest time arrives. The local government vigorously implements the strategy of "strong wind power, strong county ", which also boosts the rapid development of the secondary and tertiary industries, thus there is a dire lack of labor force in all walks of life. This caters to the psychology of some school girls and their parents, combined with the concept that "learning is useless", they choose to drop out of school actively or passively by the excuse of earning money to supplement the family.

(3) The impact of religious belief. There are a large number of ethnic minorities such as Dongxiang nationality, Hui nationality, and Tibetan nationality in the immigrants in Guazhou County, accounting for $34.4 \%$ of the total number of immigrants. Influenced by religious practices, many girls have been engaged or even married at the age of fourteen or fifteen, which directly affects the completion of the girls' education.

\section{DISCUSSION AND SUGGESTIONS}

\subsection{Intensify Immigrant Poverty Alleviation, Increase the Income of Immigrants.}

From the above analysis, we can easily see that family income directly affects the educational opportunities and educational degree of girls. To fundamentally solve the problem of girls dropping out of school, it is necessary to increase the income of migrants. Governments at all levels should actively play a leading role, make full use of the national and provincial support policies to further promote the crucial poverty alleviation work of the immigrant district. Combined with the reality and characteristics of the economic development of the immigrant district, apart from completing the dangerous old housing reconstruction, land improvement, road pavements and other infrastructure constructions in the migration area, strengthen the employment skills training and transition work of immigrants, encourage and support the migrants to be engaged in second and third industries, improve effectively the survivability and the ability to get rich of the immigrants, consolidate the basis of getting rich for the immigrants. Only by increasing the incomes of the immigrants, can the girls' education obtain a stable economic support.

\subsection{Change the Education Concept of Parents, Make Them Attach Importance to the Education of the Girls.}

As an important place for girls to grow up, the family plays a decisive role, especially the factors such as the parental educational concept, parental education degree, and their own qualities directly or indirectly affect the success and quality of girls' education. Give full play to the role of the government, the education department, and the schools, through radio, parents' meetings, home visits, training classes for parents, and other forms to propagandize vigorously the education policies of the party and the state, and other free-of-charge education policies and the subsidy policy to change the parental education concept, guide them to treat the girls' education correctly, raise the consciousness of sending girls to school; intensify the propaganda work, take the necessary legal measures, guarantee the right to receive the nine-year compulsory education of girls. 


\subsection{Strengthen the School Routine Management, Improve the Quality of Teachers.}

The importance of environment and system for the education is self-evident. As a main place for the students to learn and grow, the school has a great influence on the physical and mental health of girls. Government and relevant departments should support the standardization construction of rural immigrant schools, give priority in terms of funds and policy, guarantee the standard development and efficient operation of rural schools in compulsory education stage, constantly narrow the gap in running a school; the schools should strengthen selfconstruction and management, cultivate a good school spirit and study style, foster an excellent teaching style, strengthen the construction of teaching virtues and styles, strengthen the training of young teachers to make them grow and mature as soon as possible; carry out psychological health education to help girls to adapt to the new environment as soon as possible, ease effectively the psychological problems in study and life, and promote the harmonious development of physical and mental health.

\subsection{Deepen the Teaching Reform, Attempt Curriculum Reform.}

The detachment of the curriculum setting and the actual needs of students is an important reason for the girls' school failure and dropout. The principal MerByTemAon who is in charge of girls' education problem of the World Bank's Human Development Network points out that "so far, all efforts are put on the enrollment rate (increase the girls' enrollment rate) rather than their grades. People should also focus on the actual learning situation of the girls in the school". To change the dilemma of girls' poor education efficiency, and the high dropout rate, it is necessary to start from the reform of school teaching level, according to the actual demands of rural economic development and farmers of the immigrant region, under the premise of the strict enforcement of compulsory education program, adjust the teaching content properly, change the teaching strategies, permeate practical and technical education organically, improve the pertinence and attractiveness of school education, thus not only lay the foundation for the students to enter a higher school, but also create the necessary conditions for the students to engage in agricultural production and management in the future, which is also the inherent requirement of quality education idea.

\subsection{Build UP the Social Joint Force of "Controlling the Dropout Rate ", Reinhence the Stopping of "Dropping OUT of School"}

The family, school and society reasons are not the single reason for the girl dropouts in immigrant district. In order to fundamentally solve the problem of girls dropping out of school, it is necessary for the government, administrative department for education, schools and religious circles to work together to form a joint force of "promoting learning", building a harmonious and orderly educational pattern. Do the process supervision well, and adhere to the reporting system. Put the implement of making the dropouts back to school as an important content of the assessment of township government, supervise urge parents to ensure the timely enrollment of school-age girls according to the law; check the number of immigrants, perfect the population files; respect fully the religious beliefs, customs and habits of the immigrant masses, strive for the support and help of the local influential religious people to lay a good mass base of carrying out girl education.

\section{ACKNOWLEDGEMENTS}

This work was financially supported by the General Project of Humanities and Social Sciences, Ministry of Education (No.12YJB880024).

\section{REFERENCES}

[1] Zheng, Z.Z. Analysis of Factors Affecting the School Attendance of Chinese Teenagers Aged Ten to Eighteen. Journal of Population Education 2002(4).

[2] Qiang, H.Y. Development and Comparison of the Chinese and Foreign Women Education. Shanxi People's Education Press 2002:216.

[3] Jia, X.H. Problems and Countermeasures of Girls' Education in the Construction of New Socialist Countryside. Chinese School Education (theory) 2008(11). 